\title{
Programa Bolsa Família e indicadores educacionais em crianças, adolescentes e escolas no Brasil: revisão sistemática
}

\author{
The Bolsa Família Program and educational indicators of children, \\ adolescents, and schools in Brazil: a systematic review
}

Mariana Cristina Silva Santos (https://orcid.org/0000-0002-4962-8769) ${ }^{1}$

Lucas Rocha Delatorre (https://orcid.org/0000-0002-8410-4549) ${ }^{2}$

Maria das Graças Braga Ceccato (https://orcid.org/0000-0002-4340-0659) ${ }^{3}$

Palmira de Fátima Bonolo (https://orcid.org/0000-0003-2744-7139) ${ }^{4}$
${ }^{1}$ Programa de PósGraduação em Saúde e Nutrição, Escola de Nutrição, Universidade Federal de Ouro Preto (UFOP). Campus Universitário Morro do Cruzeiro s/n, Bauxitasantos. 35400-000 Ouro Preto MG Brasil.

marianacs@gmail.com

${ }^{2}$ Escola de Medicina, UFOP. Ouro Preto MG Brasil.

${ }^{3}$ Departamento de Farmácia Social, Faculdade de Farmácia, Universidade Federal de Minas Gerais (UFMG). Belo Horizonte MG Brasil.

${ }^{4}$ Departamento de Medicina Preventiva e Social, Faculdade de Medicina, UFMG. Belo Horizonte MG Brasil.

\begin{abstract}
The "Bolsa Familia" Program (BFP) is an income transfer program based on meeting certain conditions, being Brazil's main strategy for combating extreme poverty, hunger and social inequality. To satisfy the educational criteria, the offspring of the beneficiary families must attend school and score minimum school attendance rates. The aim of this study was to conduct a systematic review to assess the outcomes (effects and impact) of the BFP on educational indicators among the beneficiary families. A search was conducted in the Medline, Lilacs, EBSCO, Econstor, Science Direct and Web of Knowledge databases and the methodological quality of the articles included was evaluated using the Downs \& Black checklist. Of the 2,391 studies identified, only 12 were selected. There was evidence that BFP had positive outcomes on educational indicators for the female gender and for the Northern region of Brazil. The results showed that BFP has no impact on academic proficiency and performance, but has a significant impact on school attendance and dropout rates.
\end{abstract}

Key words Poverty, Effectiveness, Social iniquity, Systematic review
Resumo O Programa Bolsa Família (PBF) é de transferência condicionada de renda, sendo a principal estratégia do Brasil para o combate à pobreza extrema, à fome e à desigualdade social. As condicionalidades na educação propiciam as condições de escolarização para os beneficiários. $O$ objetivo do estudo foi realizar uma revisão sistemática para avaliar os desfechos (efeitos e impactos) do Programa Bolsa Família em indicadores educacionais entre os beneficiários. Foram consultadas as bases Medline, Lilacs, EBSCO, Econstor, Science Direct e Web of Knowledge. A qualidade metodológica dos artigos incluídos foi avaliada por meio de escores da escala de Downs \& Black. Foram identificados 2.391 estudos e selecionados 12. Houve evidencias de que o PBF tem desfechos positivos em indicadores educacionais para o sexo feminino e para a Região Norte. Como resultados, demostrou-se que o PBF não tem repercussão na proficiência e no desempenho escolar, mas impacta significativamente nas taxas de abandono e na frequência escolar.

Palavras-chave Pobreza, Efetividade, Inequidade social, Revisão sistemática 


\section{Introdução}

O Programa Bolsa Família (PBF) é a principal estratégia do Brasil com o objetivo de combater a pobreza extrema, a fome e a desigualdade social ${ }^{1}$. Para isso, o Programa articula três dimensões de atuação: a transferência direta de renda, $o$ atendimento às condicionalidades e ações governamentais complementares. Para acesso a este benefício, as famílias devem assumir o compromisso das condicionalidades definidas especialmente na área da saúde e educação, tendo como objetivo básico promover o acesso à rede de serviços públicos de saúde, assistência social e educação $0^{2,3}$.

Com isso, o PBF busca propiciar a inclusão social das famílias tornando-se ferramenta de oportunidades e emancipação das condições de pobreza, melhoria das condições de saúde e insegurança alimentar e aumento da renda familiar (sem desestímulo na participação no mercado de trabalho e sem distorção na escolha da ocupação de trabalho formal ou informal $)^{4-8}$. Na educação, o acompanhamento das condicionalidades propicia as condições de escolarização necessárias para o exercício da cidadania, possibilitando o monitoramento individual da frequência escolar em crianças e adolescentes e, quando presente, $o$ motivo de baixa frequência ${ }^{2}$.

Nas avaliações em países de baixa e média renda, as intervenções precoces no desenvolvimento infantil, como apoio dos pais e da escola, combinados com o recebimento dos benefícios tem o potencial de contribuir para a redução das desigualdades perpetuadas pela pobreza além de melhorarem as chances de matrícula e frequência escolar'. A melhora significativa destes indicadores educacionais junto à população em vulnerabilidade social pode trazer grandes repercussões sociais, com impactos positivos na renda e sua distribuição, no bem-estar e na cidadania ${ }^{10}$. No entanto, não há um consenso sumarizado em como as políticas voltadas à garantia de acesso e igualdade de oportunidades impactam sobre os sistemas educacionais brasileiros ${ }^{10,11}$.

Os avanços das políticas e gestão da educação nacional e de transferência de renda demonstra o panorama brasileiro marcado por desigualdades regionais no acesso e permanência de estudantes à educação, sendo a garantia do direito à educação de qualidade um princípio fundamental que baliza estes avanços. Assim, a condicionalidade do PBF proporciona consonância com as demais políticas de educação, tal como o Plano Nacional da Educação (PNE) uma vez que prioriza repercutir nos desafios de melhoria do acesso e perma- nência em todos os níveis, etapas e modalidades da universalização da educação básica ${ }^{12,13}$.

Dada a importância da inserção de crianças e jovens no sistema educacional, sobretudo na permanência e desenvolvimento escolar, indicadores escolares são uma forma de avaliação direta da finalidade do PBF na educação. Estas avaliações de impactos do PBF têm mostrado resultados díspares, não havendo, até o presente, uma análise sintética em nível de evidência dos resultados obtidos. Assim, considerando a necessidade de explorar e sumarizar o tema impacto e efeito do PBF sobre os indicadores educacionais, esta revisão sistemática teve como objetivo determinar se o PBF do Governo Federal produz desfechos (efeitos e impactos) positivos na educação de seus beneficiários, enfocando aspectos relacionados à frequência, matrícula, evasão, aprovação, atraso e desempenho escolar.

\section{Métodos}

Realizou-se uma revisão sistemática da literatura científica dos trabalhos publicados a respeito do efeito e do impacto do Programa Bolsa Família relacionado ao aspecto educação. A questão norteadora deste trabalho foi identificar quais seriam as evidências científicas disponíveis de que o Programa Bolsa Família promoveria impacto ou efeito nos indicadores educacionais em crianças, adolescentes e também na instituição (escola). Consideraram-se como "efeito" as mensurações que tratavam apenas de mudanças e/ou modificações de variáveis relevantes ao longo do tempo; e como "impacto" as avaliações que utilizaram grupos de comparação ou controles. Buscou-se artigos indexados nas bases eletrônicas na área da saúde, educação e de caráter multidisciplinar, tais como: Literatura Latino-Americana e do Caribe em Ciências em Saúde (Lilacs), Nacional Library of Medicine and the Nacional Institutos Health (PubMed), EBSCO, Econstor, Science Direct e Web of Knowledge. Foram ainda realizadas buscas manuais em periódicos citados nos artigos selecionados e uma busca na literatura cinzenta, no portal da Biblioteca Digital Brasileira de Teses e Dissertações (BDBTD) e no banco de dados da Coordenação de Aperfeiçoamento de Pessoal de Nível Superior (CAPES).

Os descritores utilizados foram combinados entre si com auxílio dos operadores booleanos, tais como: "transferência de renda condicionada", "programa bolsa família", "avaliação", "impacto", "efeito", "desempenho escolar", "matrícula es- 
colar”, “abandono escolar”, “aprovação escolar”, "evasão escolar", "defasagem escolar” (entre série e idade), "atraso escolar" e "indicador educacional”. Ressalta-se que o termo abandono referese ao aluno que não conseguiu finalizar o ano letivo e o termo evasão como o aluno que não conseguiu efetuar matrícula do ano posterior ao abandono. A seleção dos estudos (publicados em inglês, português e espanhol) foi restrita a trabalhos publicados entre janeiro de 2004 e dezembro de 2014, devido à data de criação do PBF pela Lei $\mathrm{n}^{\mathrm{o}} 10.836$ de 9 de janeiro de $2004^{1}$.

Foram incluídos estudos que obtiveram resultados elaborados a partir de fontes primárias ou secundárias obtidas a partir de pesquisas amostrais complexas (tais como Pesquisa Nacional de Amostras de Domicílios (PNAD) e/ou Censo Escolar). Houve avaliação de estudos referentes à faixa etária de crianças e jovens de seis a 17 anos, por ser esta correspondente aos critérios da condicionalidade educação. Foram incluídos estudos quase experimentais, ou seja, estudos com delineamentos em que não foi possível obter um controle completo e que não houve distribuição aleatória na seleção entre dos grupos ${ }^{14}$. E também estudos que obtiveram a medida do indicador educacional por meio de dados diretos da direção escolar, exames de desempenho escolar padronizado - Índice de Desenvolvimento da Educação Básica (Ideb) ou Prova Brasil, Censo Escolar ou órgão governamental diretamente superior à escola.

Além disso, foram excluídos na revisão estudos que avaliaram indicadores educacionais de outros programas de transferência de renda, com população acima de 17 anos, artigos de revisão ou de relato de caso. Por meio da leitura do título e resumo, foram avaliados os trabalhos que apresentavam características referentes à pergunta norteadora da pesquisa. A seleção e a identificação dos trabalhos foram realizadas por dois pesquisadores de forma independente, que procederam à seleção inicial pelos títulos localizados e, posteriormente, a análise do resumo. Nos casos em que se identificou a falta de informação relevante nos estudos, realizou-se o contato com os autores do trabalho por meio eletrônico de forma a solicitá-los. Aqueles que atenderam ao critério de avaliação de impacto ou efeito do PBF na educação foram analisados na íntegra.

Os dados de cada trabalho foram coletados, independentemente, em uma planilha no programa Microsoft Office Excel 2010 (Microsoft Cor, Estados Unidos $)^{15}$ em que foram registrados dados como: título, autores, revista, local, ano de publicação, características da amostra (número de participantes, grupo controle), período de referência do estudo, variáveis independentes e dependentes, método de análise, medida de associação e desfecho. Os procedimentos adotados integram as recomendações propostas por centros de excelência na produção dessa evidência, recomendados pela Cochrane Collaboration ${ }^{16} \mathrm{e}$ pelo Preferred Reporting Items for Systematic Reviews and Meta-Analysis (PRISMA) ${ }^{17}$.

Após a seleção dos pesquisadores, os trabalhos foram avaliados quanto à qualidade metodológica pontuada de acordo com os critérios de avaliação de Downs \& Black ${ }^{18}$ adaptada para estudos com delineamento não experimental. Foram utilizados 17 dos 27 itens originais estruturados em perguntas e agrupados em quatro categorias: relato do estudo (clareza); validade externa (representatividade), validade interna (vieses e fatores confundidores) e poder de efeito ou estatístico do estudo. As respostas foram pontuadas com o valor "1" (quando o critério que caracterizasse qualidade estivesse presente) ou " 0 " (quando o critério que caracterizasse qualidade estivesse ausente). O sistema de classificação adaptado indica a qualidade do estudo com escores de zero (pior qualidade) a 17 (melhor qualidade).

\section{Resultados}

A pesquisa eletrônica em diferentes bases de dados forneceu um total de 2.391 publicações, sete artigos pela busca manual e 98 teses e dissertações, como demonstra a Figura 1. Após a eliminação de 175 artigos (7,3\%) duplicados e a análise por meio da leitura do título e resumo, foram excluídos os trabalhos que não apresentavam características referentes à pergunta norteadora da pesquisa (população estudada, tipo de intervenção ou desfecho). Deste modo, 51 (2,1\%) estudos foram selecionados para a leitura completa e, ao final, foram selecionados 12 que atenderam aos critérios de inclusão, sendo nove artigos e três dissertações.

O Quadro 1 traz informações sobre os estudos incluídos nesta revisão. Dos 12 trabalhos que preenchiam os critérios de inclusão, três artigos foram publicados em inglês e nove na língua portuguesa, sendo que oito estudos foram realizados a nível nacional, dois na região nordeste e dois na região de São Paulo.

A maior parte dos estudos $(n=8)$ utilizou como unidade de avaliação do Programa Bolsa Família, o aluno, enquanto que os demais utiliza- 

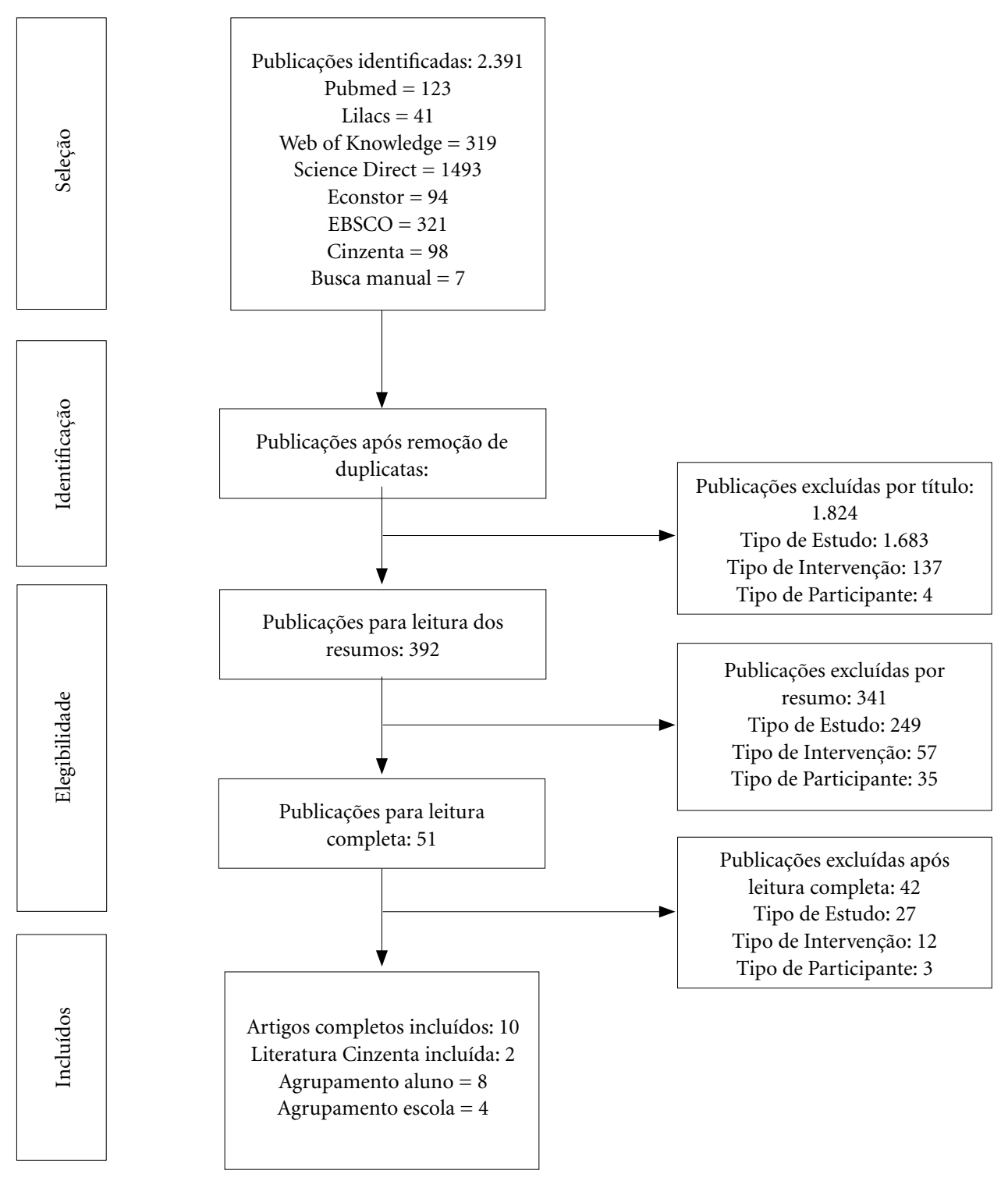

Figura 1. Fluxograma das etapas de seleção para estruturação de estudos da revisão sistemática.

ram a escola como unidade de análise. Isso significa que as crianças são a unidade de observação dos bancos de dados e que foram analisadas de acordo com o seu contexto familiar, domiciliar, saúde, educação, ocupação e outros. Os estudos que utilizaram a escola como unidade de observação, avaliaram como o percentual de alunos beneficiários do PBF nas escolas exerce efeito no contexto de avaliação das instituições por meio do Censo Escolar e índices educacionais. Os estudos que avaliaram o impacto e, portanto, utilizaram um grupo de comparação $(n=7)$ adotaram grupos de tratamentos como sendo o grupo exposto à intervenção do $\mathrm{PBF}$. Os resultados para as análises dos indicadores foram agrupados em frequência escolar e abandono escolar; matrícula e evasão escolar; aprovação, atraso e desempenho escolar. 
Quadro 1. Descrição dos estudos selecionados para a revisão sistemática.

\begin{tabular}{|c|c|c|c|c|c|c|c|c|}
\hline Referência & $\begin{array}{c}\text { Local } \\
\text { (Período) }\end{array}$ & $\begin{array}{c}\text { Unidade } \\
\text { de } \\
\text { Análise }\end{array}$ & $\begin{array}{c}\text { Grupo de } \\
\text { comparação }\end{array}$ & $\begin{array}{c}\text { Variável } \\
\text { dependente / } \\
\text { Independentes }\end{array}$ & $\begin{array}{c}\text { Indicador } \\
\text { Educacional }\end{array}$ & Medida & p-valor & Desfecho \\
\hline \multirow[t]{2}{*}{$\begin{array}{l}\text { Amaral e } \\
\text { Monteiro } \\
(2013)^{25}\end{array}$} & \multirow[t]{2}{*}{$\begin{array}{l}\text { Nacional } \\
\text { (2005 e } \\
2009)\end{array}$} & \multirow[t]{2}{*}{ Aluno } & \multirow[t]{2}{*}{ Sim } & \multirow[t]{2}{*}{$\begin{array}{l}\text { Evasão escolar } \\
\text { / Participação } \\
\text { no PBF, } \\
\text { características } \\
\text { do domicílio, } \\
\text { da mãe e da } \\
\text { criança }\end{array}$} & $\begin{array}{l}\text { Evasão } \\
(2005)\end{array}$ & 0,663 & $\mathrm{p}<0,05$ & \multirow{2}{*}{$\begin{array}{l}\text { Em curto } \\
\text { prazo o PBF } \\
\text { teve efeito } \\
\text { significativo } \\
\text { na redução da } \\
\text { evasão escolar } \\
\text { de crianças } \\
\text { beneficiárias. } \\
\text { Em médio } \\
\text { prazo não } \\
\text { houve } \\
\text { significância, } \\
\text { apesar do } \\
\text { apontamento } \\
\text { para a } \\
\text { diminuição da } \\
\text { evasão escolar }\end{array}$} \\
\hline & & & & & $\begin{array}{l}\text { Evasão } \\
(2009)\end{array}$ & 0,921 & & \\
\hline \multirow[t]{2}{*}{$\begin{array}{l}\text { Melo e } \\
\text { Duarte } \\
(2010)^{19}\end{array}$} & \multirow[t]{2}{*}{$\begin{array}{l}\text { PE, CE, } \\
\text { PB e Se } \\
(2005)\end{array}$} & \multirow[t]{2}{*}{ Aluno } & \multirow[t]{2}{*}{ Sim } & \multirow{2}{*}{$\begin{array}{l}\text { Participação do } \\
\text { PBF/Frequência } \\
\text { escolar, sexo, } \\
\text { idade, renda, } \\
\text { escolaridade } \\
\text { dos pais, } \\
\text { número de } \\
\text { filhos }\end{array}$} & $\begin{array}{l}\text { Frequência } \\
\text { (amostra } \\
\text { campo) }\end{array}$ & 0,056 & $\mathrm{p}<0,05$ & \multirow{2}{*}{$\begin{array}{l}\text { Impacto } \\
\text { positivo e } \\
\text { significativo } \\
\text { do PBF na } \\
\text { frequência } \\
\text { escolar }\end{array}$} \\
\hline & & & & & $\begin{array}{l}\text { Frequência } \\
\text { (amostra } \\
\text { PNAD) }\end{array}$ & 0,218 & $\mathrm{p}<0,05$ & \\
\hline \multirow[t]{4}{*}{$\begin{array}{l}\text { Ribeiro e } \\
\text { Cacciamali } \\
(2012)^{28}\end{array}$} & \multirow[t]{4}{*}{$\begin{array}{l}\text { Nacional } \\
(2006)\end{array}$} & \multirow[t]{4}{*}{ Aluno } & \multirow[t]{4}{*}{ Sim } & \multirow{4}{*}{$\begin{array}{l}\text { Ausência escolar } \\
\text { (proporção) e } \\
\text { atraso escolar } \\
\text { (razão) / } \\
\text { Localização } \\
\text { (urbana } \\
\text { e rural), } \\
\text { participação no } \\
\text { PBF, sexo, raça, } \\
\text { renda }\end{array}$} & $\begin{array}{l}\text { Ausência } \\
\text { (zona } \\
\text { urbana) }\end{array}$ & 0,0069 & 0,538 & \multirow{4}{*}{\begin{tabular}{|l} 
Sem impacto \\
na ausência \\
escolar e as \\
diferenças \\
para o atraso \\
escolar \\
não são \\
significativas, \\
tanto para o \\
meio urbano \\
quanto para o \\
meio rural
\end{tabular}} \\
\hline & & & & & $\begin{array}{l}\text { Ausência } \\
\text { (zona rural) }\end{array}$ & 0,0167 & 0,487 & \\
\hline & & & & & $\begin{array}{l}\text { Atraso (zona } \\
\text { urbana) }\end{array}$ & $-0,0105$ & 0,151 & \\
\hline & & & & & $\begin{array}{l}\text { Atraso (zona } \\
\text { rural) }\end{array}$ & 0,0206 & 0,379 & \\
\hline $\begin{array}{l}\text { Cacciamali } \\
\text { et al. } \\
(2010)^{26}\end{array}$ & $\begin{array}{l}\text { Nacional } \\
(2004)\end{array}$ & Aluno & Sim & $\begin{array}{l}\text { Matrícula / } \\
\text { recebimento do } \\
\text { PBF, anos de } \\
\text { escolaridade, } \\
\text { idade, sexo, } \\
\text { ocupação, } \\
\text { região do país, } \\
\text { localização } \\
\text { (urbana ou } \\
\text { rural) }\end{array}$ & Evasão & 1,36 & $\mathrm{p}<0,10$ & $\begin{array}{l}\text { Aumento da } \\
\text { frequência } \\
\text { escolar e sem } \\
\text { efeito sobre } \\
\text { o trabalho } \\
\text { infantil. }\end{array}$ \\
\hline
\end{tabular}

\section{Frequência e abandono escolar}

Os estudos que avaliaram a frequência esco$\operatorname{lar}(\mathrm{n}=4)$, tendo como unidade de análise o alu- no, obtiveram impactos positivos e significativos para os beneficiários. De acordo com o Quadro 1 , dois trabalhos incluíram crianças que residiam no meio rural, com renda domiciliar per capi- 
Quadro 1. Descrição dos estudos selecionados para a revisão sistemática.

\begin{tabular}{|c|c|c|c|c|c|c|c|c|}
\hline Referência & $\begin{array}{c}\text { Local } \\
\text { (Período) }\end{array}$ & $\begin{array}{c}\text { Unidade } \\
\text { de } \\
\text { Análise }\end{array}$ & $\begin{array}{c}\text { Grupo de } \\
\text { comparação }\end{array}$ & \begin{tabular}{|c|} 
Variável \\
dependente / \\
Independentes
\end{tabular} & $\begin{array}{l}\text { Indicador } \\
\text { Educacional }\end{array}$ & Medida & p-valor & Desfecho \\
\hline $\begin{array}{l}\text { Oliveira } \\
\text { e Soares } \\
(2013)^{27}\end{array}$ & $\begin{array}{l}\text { Nacional } \\
(2008 \mathrm{e} \\
2009)\end{array}$ & Aluno & Não & $\begin{array}{l}\text { Repetência / } \\
\text { repetência no } \\
\text { ano anterior, } \\
\text { sexo, defasagem, } \\
\text { recebimento do } \\
\text { PBF }\end{array}$ & Repetência & 0,89 & 0,0136 & $\begin{array}{l}\text { PBF tem } \\
\text { impacto } \\
\text { significativo } \\
\text { sobre a } \\
\text { progressão } \\
\text { das crianças, } \\
\text { embora o } \\
\text { mesmo seja } \\
\text { relativamente } \\
\text { modesto. } \\
\end{array}$ \\
\hline \multirow{4}{*}{$\begin{array}{l}\text { Cavalcanti } \\
\text { et al. } \\
(2013)^{20}\end{array}$} & \multirow{4}{*}{$\begin{array}{l}\text { Nordeste } \\
(2004 \text { e } \\
2006)\end{array}$} & \multirow[t]{4}{*}{ Aluno } & \multirow[t]{4}{*}{ Sim } & \multirow{4}{*}{$\begin{array}{l}\text { Participação } \\
\text { PBF / } \\
\text { frequência } \\
\text { escolar, sexo, } \\
\text { merenda } \\
\text { gratuita, rede de } \\
\text { ensino, trabalho } \\
\text { infantil, anos de } \\
\text { estudo dos pais }\end{array}$} & $\begin{array}{l}\text { Frequência } \\
\text { (FP 2004) }\end{array}$ & 0,341 & $\mathrm{p}<0,01$ & \multirow{4}{*}{$\begin{array}{l}\text { Impacto } \\
\text { significativo } \\
\text { e positivo } \\
\text { em favor dos } \\
\text { tratados, mas } \\
\text { o aumento se } \\
\text { dá em taxas } \\
\text { decrescentes }\end{array}$} \\
\hline & & & & & $\begin{array}{l}\text { Frequência } \\
\text { (FP 2006) }\end{array}$ & 0,261 & $\mathrm{p}<0,01$ & \\
\hline & & & & & \begin{tabular}{|l}
$\begin{array}{l}\text { Frequência } \\
\text { (FEP 2004) }\end{array}$ \\
\end{tabular} & 0,399 & $\mathrm{p}<0,01$ & \\
\hline & & & & & $\begin{array}{l}\text { Frequência } \\
\text { (FEP 2006) }\end{array}$ & 0,267 & $\mathrm{p}<0,01$ & \\
\hline \multirow[t]{2}{*}{$\begin{array}{l}\text { Santarrosa } \\
(2011)^{29}\end{array}$} & \multirow{2}{*}{$\begin{array}{l}\text { São Paulo } \\
(2007, \\
2008, \\
2009)\end{array}$} & \multirow[t]{2}{*}{ Aluno } & \multirow[t]{2}{*}{ Sim } & \multirow{2}{*}{$\begin{array}{l}\text { Proficiência } \\
\text { em Matemática } \\
\text { e Português/ } \\
\text { participação } \\
\text { no PBF, sexo, } \\
\text { idade, série, } \\
\text { faixa de renda, } \\
\text { escolaridade e } \\
\text { ocupação dos } \\
\text { pais }\end{array}$} & $\begin{array}{l}\text { Proficiência } \\
\text { em Português }\end{array}$ & 2,467 & $\mathrm{p}<0,10$ & \multirow{2}{*}{$\begin{array}{l}\text { Sem } \\
\text { impacto na } \\
\text { proficiência } \\
\text { em } \\
\text { matemática } \\
\text { e impacto } \\
\text { positivo } \\
\text { marginal na } \\
\text { proficiência } \\
\text { em português. }\end{array}$} \\
\hline & & & & & $\begin{array}{l}\text { Proficiência } \\
\text { em } \\
\text { Matemática }\end{array}$ & $-0,656$ & - & \\
\hline \multirow[t]{6}{*}{$\begin{array}{l}\text { Pellegrina } \\
(2011)^{21}\end{array}$} & \multirow{6}{*}{$\begin{array}{l}\text { São Paulo } \\
(2007, \\
2008, \\
2009)\end{array}$} & \multirow[t]{6}{*}{ Aluno } & \multirow[t]{6}{*}{ Sim } & \multirow{6}{*}{$\begin{array}{l}\text { Evasão, } \\
\text { Frequência e } \\
\text { Desempenho/ } \\
\text { participação } \\
\text { no PBF, } \\
\text { características } \\
\text { socioeconômicas }\end{array}$} & $\begin{array}{l}\text { Frequência } \\
\text { (ausência) }\end{array}$ & $-0,353$ & $\mathrm{p}<0,01$ & \multirow{6}{*}{$\begin{array}{l}\text { Impacto } \\
\text { significativo } \\
\text { sobre o } \\
\text { abandono } \\
\text { escolar. Para o } \\
\text { desempenho, } \\
\text { o impacto foi } \\
\text { nulo }\end{array}$} \\
\hline & & & & & Evasão & $-0,313$ & $\mathrm{p}<0,10$ & \\
\hline & & & & & $\begin{array}{l}\text { Proficiência } \\
\text { Matemática } \\
\text { (boletim) }\end{array}$ & $-0,039$ & - & \\
\hline & & & & & \begin{tabular}{|l} 
Proficiência \\
em Português \\
(boletim)
\end{tabular} & 0,450 & - & \\
\hline & & & & & $\begin{array}{l}\text { Proficiência } \\
\text { Matemática } \\
\text { (exame } \\
\text { padronizado) }\end{array}$ & 0,004 & - & \\
\hline & & & & & $\begin{array}{l}\text { Proficiência } \\
\text { em Português } \\
\text { (exame } \\
\text { padronizado) }\end{array}$ & $-0,003$ & - & \\
\hline
\end{tabular}

ta mensal semelhante entre os grupos e, ainda, crianças do meio urbano/rural com rendas equiparadas (após ajuste de discrepâncias), respectivamente. Em ambos, o impacto do PBF foi posi- tivo na assiduidade de aulas dos alunos na região nordeste, porém em taxas decrescentes, de 2004 para 2006 e de amostras PNAD para amostras provenientes de campo (fontes primárias) ${ }^{19,20}$. 
Quadro 1. Descrição dos estudos selecionados para a revisão sistemática.

\begin{tabular}{|c|c|c|c|c|c|c|c|c|}
\hline Referência & $\begin{array}{c}\text { Local } \\
\text { (Período) }\end{array}$ & $\begin{array}{c}\text { Unidade } \\
\text { de } \\
\text { Análise }\end{array}$ & $\begin{array}{c}\text { Grupo de } \\
\text { comparação }\end{array}$ & \begin{tabular}{|c|} 
Variável \\
dependente / \\
Independentes
\end{tabular} & $\begin{array}{c}\text { Indicador } \\
\text { Educacional }\end{array}$ & Medida & p-valor & Desfecho \\
\hline \multirow[t]{2}{*}{$\begin{array}{l}\text { Duarte } \\
(2013)^{30}\end{array}$} & \multirow[t]{2}{*}{$\begin{array}{l}\text { Nacional } \\
(2009)\end{array}$} & \multirow[t]{2}{*}{ Escola } & \multirow[t]{2}{*}{ Não } & \multirow{2}{*}{$\begin{array}{l}\text { IDEB } 2009 \\
\text { / percentual } \\
\text { de alunos } \\
\text { beneficiários, } \\
\text { PIB per capita } \\
\text { do município } \\
\text { e porte do } \\
\text { município e } \\
\text { custo-aluno. }\end{array}$} & $\begin{array}{l}\text { Ide } 2009 \\
\text { (Nível 1) }\end{array}$ & $-0,42$ & - & \multirow[t]{2}{*}{$\begin{array}{l}\text { Impacto } \\
\text { negativo } \\
\text { da \% de } \\
\text { beneficiários } \\
\text { do PBF no } \\
\text { IDEB. }\end{array}$} \\
\hline & & & & & $\begin{array}{l}\text { Ide } 2009 \\
\text { (Nível 2) }\end{array}$ & $-0,29$ & - & \\
\hline \multirow[t]{3}{*}{$\begin{array}{l}\text { Glewwe e } \\
\text { Kassouf } \\
(2012)^{22}\end{array}$} & \multirow[t]{3}{*}{$\begin{array}{l}\text { Nacional } \\
(1998- \\
2005)\end{array}$} & \multirow[t]{3}{*}{ Escola } & \multirow[t]{3}{*}{ Não } & \multirow{3}{*}{$\begin{array}{l}\text { Taxas de } \\
\text { matrícula, } \\
\text { abandono e } \\
\text { aprovação } \\
\text { / escolas } \\
\text { com alunos } \\
\text { participando do } \\
\text { PBF, estrutura } \\
\text { da escola }\end{array}$} & Matrícula & 0,033 & $\mathrm{p}<0,01$ & \multirow{3}{*}{$\begin{array}{l}\text { Para escolas, } \\
\text { o impacto } \\
\text { para os três } \\
\text { indicadores } \\
\text { é altamente } \\
\text { significativo } \\
\text { e com sinal } \\
\text { positivo. }\end{array}$} \\
\hline & & & & & Abandono & $-0,582$ & $\mathrm{p}<0,01$ & \\
\hline & & & & & Aprovação & 0,721 & $\mathrm{p}<0,01$ & \\
\hline \multirow[t]{4}{*}{$\begin{array}{l}\text { Camargo } \\
\text { e Pazello } \\
(2014)^{24}\end{array}$} & \multirow[t]{4}{*}{$\begin{array}{l}\text { Nacional } \\
(2008 \mathrm{e} \\
2009)\end{array}$} & \multirow[t]{4}{*}{ Escola } & \multirow[t]{4}{*}{ Não } & \multirow{4}{*}{$\begin{array}{l}\text { Taxa de } \\
\text { aprovação, } \\
\text { abandono e } \\
\text { desempenho } \\
\text { da escola/sexo, } \\
\text { etnia, moradia } \\
\text { rural ou urbana, } \\
\text { estado, tamanho } \\
\text { do município, } \\
\text { proporção } \\
\text { de alunos } \\
\text { beneficiários }\end{array}$} & Aprovação & $-0,019$ & $\mathrm{p}<0,01$ & \multirow{4}{*}{$\begin{array}{l}\text { Escolas com } \\
\text { proporção } \\
\text { maior de } \\
\text { alunos } \\
\text { beneficiários } \\
\text { têm menores } \\
\text { taxas de } \\
\text { aprovação, } \\
\text { taxa de } \\
\text { abandono e } \\
\text { proficiência } \\
\text { média, } \\
\text { sugerindo } \\
\text { relação causal } \\
\text { significativa e } \\
\text { negativa. }\end{array}$} \\
\hline & & & & & Abandono & $-0,014$ & $\mathrm{p}<0,01$ & \\
\hline & & & & & $\begin{array}{l}\text { Desempenho } \\
\text { Matemática }\end{array}$ & $-0,170$ & $\mathrm{p}<0,01$ & \\
\hline & & & & & $\begin{array}{l}\text { Desempenho } \\
\text { Português }\end{array}$ & $-0,163$ & $\mathrm{p}<0,01$ & \\
\hline
\end{tabular}


Quadro 1. Descrição dos estudos selecionados para a revisão sistemática.

\begin{tabular}{|c|c|c|c|c|c|c|c|c|}
\hline Referência & $\begin{array}{c}\text { Local } \\
\text { (Período) }\end{array}$ & $\begin{array}{c}\text { Unidade } \\
\text { de } \\
\text { Análise }\end{array}$ & $\begin{array}{c}\text { Grupo de } \\
\text { comparação }\end{array}$ & $\begin{array}{c}\text { Variável } \\
\text { dependente / } \\
\text { Independentes }\end{array}$ & $\begin{array}{c}\text { Indicador } \\
\text { Educacional }\end{array}$ & Medida & p-valor & Desfecho \\
\hline \multirow[t]{8}{*}{$\begin{array}{l}\text { Simões e } \\
\text { Sabates } \\
(2014)^{23}\end{array}$} & \multirow[t]{8}{*}{$\begin{array}{l}\text { Nacional } \\
(2005 \text { e } \\
2007)\end{array}$} & \multirow[t]{8}{*}{ Escola } & \multirow[t]{8}{*}{ Não } & \multirow{8}{*}{$\begin{array}{l}\text { Proficiência } \\
\text { em Português } \\
\text { e Matemática, } \\
\text { aprovação e } \\
\text { abandono/ } \\
\text { variáveis } \\
\text { socioeconômicas, } \\
\text { características } \\
\text { dos alunos e suas } \\
\text { famílias }\end{array}$} & $\begin{array}{l}\text { Proficiência } \\
\text { Português } \\
(2005)\end{array}$ & $-0,041$ & $\mathrm{p}<0,01$ & \multirow{8}{*}{$\begin{array}{l}\text { Efeito } \\
\text { negativo da } \\
\text { proporção } \\
\text { de alunos } \\
\text { beneficiários } \\
\text { nos testes de } \\
\text { aprendizagem } \\
\text { é reduzido de } \\
\text { acordo com } \\
\text { o aumento } \\
\text { no tempo de } \\
\text { participação } \\
\text { ou no } \\
\text { aumento do } \\
\text { benefício, } \\
\text { assim como } \\
\text { para taxas de } \\
\text { abandono que } \\
\text { diminui. }\end{array}$} \\
\hline & & & & & $\begin{array}{l}\text { Proficiência } \\
\text { Português } \\
(2007)\end{array}$ & $-0,013$ & $\mathrm{p}<0,05$ & \\
\hline & & & & & $\begin{array}{l}\text { Proficiência } \\
\text { Matemática } \\
(2005)\end{array}$ & 0,002 & - & \\
\hline & & & & & $\begin{array}{l}\text { Proficiência } \\
\text { Matemática } \\
(2007)\end{array}$ & $-0,038$ & $\mathrm{p}<0,01$ & \\
\hline & & & & & \begin{tabular}{|l} 
Taxa de \\
abandono \\
$(2005)$ \\
\end{tabular} & 0,014 & $\mathrm{p}<0,01$ & \\
\hline & & & & & \begin{tabular}{|l} 
Taxa de \\
abandono \\
$(2007)$ \\
\end{tabular} & $-0,025$ & $\mathrm{p}<0,01$ & \\
\hline & & & & & \begin{tabular}{|l} 
Taxa de \\
aprovação \\
$(2005)$
\end{tabular} & $-0,015$ & $\mathrm{p}<0,05$ & \\
\hline & & & & & \begin{tabular}{|l} 
Taxa de \\
aprovação \\
$(2007)$
\end{tabular} & 0,026 & $\mathrm{p}<0,01$ & \\
\hline
\end{tabular}

*PBF: Programa Bolsa Família. PNAD: Pesquisa Nacional por Amostra de Domicílios. FEP: famílias extremamente pobres. FP: famílias pobres. Ide: Î́ndice de Desenvolvimento da Educação Básica.

A participação no PBF mostrou-se inócua entre as crianças e adolescentes que declararam deixar de comparecer às aulas no período de um bimestre com aqueles que frequentaram regularmente a escola no mesmo período. As médias de abandono escolar foram maiores na zona rural, apesar de não ter ocorrido significância estatística. Embora a magnitude do efeito tenha sido próxima a zero, o estudo de Pellegrina ${ }^{21}$ obteve resultados significativos na diminuição de pontos percentuais de aulas ausentes e taxa de abandono escolar em dados do sistema de avaliação escolar do estado de São Paulo.

Para a análise da proporção de alunos beneficiários dentro das unidades escolares, um estudo avaliou dados do Censo Escolar do ano de 2005 com escolas de $1^{\mathrm{a}}$ a $4^{\mathrm{a}}, 5^{\mathrm{a}}$ a $8^{\mathrm{a}}$ ou de $1^{\mathrm{a}}$ a $8^{\mathrm{a}}$ séries em todo o país e que prestaram informações sobre a participação alunos beneficiários ${ }^{22}$. As escolas com alunos inscritos no programa apresentaram menor de taxa de abandono escolar (0,31\%), sendo as meninas menos propensas a abandonar a escola e com taxas mais altas de frequência escolar $^{19,22}$. Ainda em 2005, e até 2007, observou-se a queda na taxa de abandono escolar por ocasião de recebimento do $\mathrm{PBF}$, chegando a 0,25 pontos percentuais para cada aumento na proporção de alunos $^{23}$. A direção destes efeitos persiste nas análises realizadas em escolas separadas em quatro grupos de percentis ( $<25 \%, 25 \%-50 \%, 50 \%$ $75 \%$ e $>75 \%$ ) de alunos beneficiários, de $3^{\circ}$ e $4^{\circ}$ série analisados a partir do Censo Escolar de 2008 que demonstraram que o aumento de um ponto percentual nessa proporção reduziu em 0,008 a taxa de abandono escolar ${ }^{24}$.

\section{Matrícula e evasão escolar}

Três estudos avaliaram a evasão escolar de forma positiva em famílias com diferentes níveis de renda e em diversas regiões do país. Os alunos beneficiários tiveram, para o ano de 2005, 34\% menos chance de abandonar a escola em crianças de famílias com limite de renda domiciliar 
correspondente a elegibilidade do PBF; para o ano de 2009 não houve resultados significativos estatisticamente, apesar de terem sempre apontado para redução da evasão escolar ${ }^{25}$. De maneira geral, no Brasil houve aumento de 1,36\% no atendimento escolar às famílias mais pobres. Em termos regionais, o maior impacto do PBF foi para região Norte $(3,5 \%)$, Centro-oeste $(2,3 \%)$ e Nordeste $(1,5 \%)^{26}$. Já o alunado do estado de São Paulo apresentou queda significativa $(-0,313$ pontos percentuais) na proporção de alunos que evadiram entre os beneficiários ${ }^{21}$.

Para as escolas de ensino fundamental com alunos inscritos no PBF também houve impacto significativo e positivo com mais matrículas (2,6\%). Este aumento teve maior relevância em escolas onde os alunos são negros (13 pontos percentuais), pardos (4 pontos percentuais) e indígenas (15 pontos percentuais). Além disso, este impacto foi menor em escolas relativamente maiores (maior taxa de matrícula) e localizadas em áreas urbanas ${ }^{22}$.

\section{Aprovação, atraso e desempenho escolar}

Um estudo avaliou a repetência para alunos beneficiários, demonstrando probabilidade de repetência de $11 \%$ menor do que os demais, além de apontar evidências de que o público que contempla o Cadastro Único para Programas Sociais do Governo Federal (CadÚnico) tem 46\% mais chance de repetir de série caso já tenham sofrido repetência no ano anterior ${ }^{27}$. De forma análoga ao indicador repetência, a defasagem idade-série (atraso escolar) não se mostrou significativa entre grupos tratamento e controle para zonas urbanas e rurais ${ }^{28}$.

Quanto à qualidade da educação, quatro estudos avaliaram o desempenho médio por meio de exames padronizados, sendo eles: Sistema de Avaliação do Rendimento Escolar do Estado de São Paulo - SARESP, Prova São Paulo e Prova Brasil $^{21,23,24,29}$. Sendo que um destes estudos, além do SARESP, examinou também as notas escolares diretamente sobre o boletim do aluno ${ }^{21}$. Com estimativas heterogêneas entre as fontes, o PBF mostrou-se significativo e impactante apenas para a Prova São Paulo em português ${ }^{29}$, sem impactos sobre a proficiência em matemática e sem diferenças significativas entre os resultados dos alunos por meio do boletim ou por meio de exames padronizados.

Para as análises realizadas com a escola, a avaliação do PBF por meio do percentual de alunos beneficiários na escola gerou impacto negativo no IDEB da escola $(-0,42)^{30}$. Em abordagens referentes à aprovação escolar, no ano de 2005 houve aumento de 0,9 ponto percentual nas escolas de $1^{\text {a }}$ a $4^{\mathrm{a}}$ série e de 0,3 ponto percentual nas escolas de $5^{\mathrm{a}}$ a $8^{\mathrm{a}}$ série na taxa de aprovação ${ }^{22}$. Para o ano de 2007, houve impacto positivo na aprovação escolar com diminuição de 0,25 pontos percentuais a cada aumento percentual de alunos beneficiários. No entanto, estimativas posteriores (2008) indicaram que o aumento da proporção de alunos do PBF reduziu em 0,048 a aprovação em escolas ${ }^{24}$.

Com relação ao desempenho das escolas na proficiência de português pela Prova Brasil, observou-se impacto negativo e significativo ao longo do intervalo de 2005 a 2007, mas com valores decrescentes. Este efeito marginal estimado na proporção de PBF sobre as pontuações dos testes é menor quanto maior é o tempo em que as famílias estão no Programa. O desempenho em matemática foi insatisfatório em todas as análises, sendo negativo e significativo para o ano de 2007 com redução de 0,038 pontos percentuais no valor do teste em alunos de $4^{\text {a }}$ série; já em 2008 em alunos da $3^{\mathrm{a}}$ e $4^{\mathrm{a}}$ série houve redução de 0,014 pontos percentuais nos testes ${ }^{23}$.

Para a avaliação da escala de qualidade Downs \& Black $^{18}$, segundo a análise dos 17 critérios (máxima 17 pontos), a mediana do escore encontrada foi de 12 pontos (mínimo de 10 e máximo de 14). A maioria dos estudos (58,4\%; n $=7$ ) obtiveram pontuação entre 10 e 12 pontos, sendo o restante $(41,6 \%, \mathrm{n}=5)$ com 13 e 14 .

A Tabela 1 apresenta o percentual de acertos para cada um dos critérios da escala adaptada de Downs e Black ${ }^{18}$. As limitações mais frequentes nos estudos foram: problemas com o tempo de seguimento para a amostra e com os valores de probabilidades que não foram relatados integralmente. Os critérios mais bem avaliados pela escala foram os que estavam relacionados ao relato de estudo (objetivos e desfechos principais claramente descritos no trabalho) e a validade externa (apresentavam testes estatísticos apropriados, desfechos com medidas válidas e análise não planejada relatada devidamente).

Para a categoria "relato de estudo", um trabalho apresentou a pontuação máxima para esse aspecto $^{27}$, no entanto, sete deles obtiveram pontuação limítrofe de seis pontos para esse quesito. Para a "validade externa", a maioria dos estudos $(58,3 \% ; \mathrm{n}=7)^{21-25,28,29}$ apresentou pontuação limítrofe de quatro pontos e somente $\mathrm{um}^{29}$ obteve pontuação abaixo de três. Para o quesito "validade interna", a maioria dos estudos $(66,6 \% ; n=8)$ 
Tabela 1. Percentual de acertos para os critérios da escala adaptada de Downs \& Black.

\begin{tabular}{lc}
\multicolumn{1}{c}{ Critérios } & Acertos (\%) $\mathbf{n}=\mathbf{1 2}$ \\
\hline Relato de estudo & 91,7 \\
Objetivos/hipótese claramente descrita & 91,7 \\
Desfechos principais medidos descritos na metodologia & 75,0 \\
Definição de casos/controles ou critérios de inclusão e exclusão & 100,0 \\
Principais achados/desfechos descritos & 91,7 \\
Variabilidade randômica dos dados para os desfechos & 58,3 \\
Perda de acompanhamento descrita & 25,0 \\
Valores reais de probabilidade reportados integralmente & \\
Validade externa & 58,3 \\
Representatividade da amostra & 100,0 \\
Análise não planejada reportada & 16,7 \\
Tempo de seguimento iguais para toda a amostra & 100,0 \\
Testes estatísticos apropriados & 91,7 \\
Medidas de desfecho válidas e confiáveis & \\
Validade interna & 83,3 \\
Indivíduos recrutados na mesma população & 33,3 \\
Indivíduos recrutados no mesmo período de tempo & 75,0 \\
Ajuste adequado para fatores de confusão na análise & 66,7 \\
Perdas de indivíduos reportados & \\
Poder do estudo & 66,7 \\
Apresenta o poder do estudo & \\
\hline
\end{tabular}

obteve pontuação limítrofe de três pontos e para o "poder do estudo", a maioria apresentou a detecção da diferença da probabilidade ter ocorrido ao acaso menor que $5 \%(66,6 \% ; n=8)$.

\section{Discussão}

Os programas de transferência de renda tornam-se relevante no cenário social nacional ao promover acesso ao serviço básico de educação, atraindo crianças em situação de vulnerabilidade social para a escola. A presente revisão sistemática reuniu estes trabalhos e duas análises principais podem ser obtidas com base nas evidências encontradas.

Primeiramente, aponta-se que independentemente da unidade de análise, se aluno ou escola, o PBF mostrou-se capaz de produzir resultados positivos para a frequência escolar e as taxas de abandono, principalmente. Apesar disso, ressalta-se que os principais motivos de abandono escolar pelos beneficiários foram a necessidade de trabalhar, seguida da falta de vontade em dar continuidade aos estudos, além da gravidez precoce entre as mulheres ${ }^{31}$. Quando a criança passa a exercer atividade remunerada para diminuir as despesas no orçamento familiar a si- tuação se agrava na medida em que a frequência escolar se torna irregular, muitas vezes seguida de atraso e desistência escolar ${ }^{10}$. Deve-se considerar que estes motivos relatados também são monitorados por outros programas do Governo (Programa de Erradicação do Trabalho Infantil - PETI, PROJOVEM Adolescente), bem como o acompanhamento em saúde, especialmente pela atenção básica à saúde. Apesar de serem motivos prioritariamente de cunho social, são passíveis de mudança por meio de intervenções de ações e programas ${ }^{32}$.

Considerando que as contrapartidas do PBF podem impactar positivamente nos aspectos quantitativos de educação, observaram-se benefícios principalmente na frequência escolar. É possível que para alunos que não frequentavam a escola, ao passar a receber o benefício este compense o aluno a não abandonar mais os estudos.

Analogicamente, para os matriculados na escola, o benefício pode contribuir na diminuição do custo de permanência na escola para a famí$\operatorname{lia}^{21}$. As despesas educacionais a que as famílias estão propensas a ter, pode consumir boa parte da renda e aumentar a chance do trabalho infantil, principalmente em famílias monoparentais chefiadas pela mãe $e^{7,10,33}$. A diferença entre gêneros também é notória com efeitos mais expressivos 
e positivos para meninas, o que em parte é explicado pela inserção mais cedo dos meninos na atividade produtiva, o que implica menor tempo de dedicação aos estudos ${ }^{34,35}$.

Em segundo lugar, o PBF ainda não se mostra capaz de repercutir de maneira satisfatória nas variáveis relacionadas com a qualidade do ensino. A avaliação e a divulgação destes resultados escolares e as metas criadas pelo estado, município e escolas não envolvem prêmios ou sanções como ocorre em alguns estados que possuem sistemas próprios de avaliação (Ceará, Pernambuco e São Paulo) ${ }^{36}$. Por exemplo, a ocorrência de impacto marginal significativo (ou seja, dependente simultaneamente de outros fatores e termos) em somente um exame padronizado (português), como no estado de São Paulo, pode estar associada também ao fato da geração de incentivos para que os professores tenham interesse no desempenho dos alunos ou por motivos intrínsecos aos alunos (como interesse próprio na aprendizagem e no conhecimento, curiosidade, busca de desafios $)^{29,36,37}$.

Para o efeito decrescente do impacto negativo em exames de proficiência (português ou matemática), os estudos sugerem que as escolas que se beneficiam com o PBF por um maior tempo se favorecem com um desempenho melhor no exame nacional ${ }^{23}$. A avaliação padronizada dos alunos nas escolas, ainda que ampliem o seu escopo, boa parte das avaliações se restringiu a leitura e matemática o que pode ser considerado algo limitante que não engloba outras habilidades não cognitivas (preservação ambiental, ética, responsabilidade social) igualmente importantes para formação dos mesmos ${ }^{37}$. Há, ainda, indícios de que alguns municípios atingiram valores do Ideb acima da média nacional, mas com resultados bons somente para alunos matriculados nas melhores escolas, evidenciando que as disparidades são comuns dentro de uma mesma rede de ensino $^{38}$. Uma vez que as assimetrias existentes entre as regiões geográficas, escolas da cidade e do campo, escolas públicas e privadas, municipais e estaduais/federais e sua capacidade de planejamento por número de aluno, escolas e insumos são evidentes ${ }^{12,39}$. Adicionalmente, para as escolas de diferentes zonas censitárias, a área rural convive com uma oferta menor de escolas e condições físicas deficientes quando comparada à área urbana com desafios e realidade educacionais diversas ${ }^{40}$.

Por outro lado, ao diminuir as chances de repetência escolar ${ }^{27}$, há de conjecturar-se que melhores desempenhos, com progressão e pouco atrasos escolares, tornam-se presumíveis quando crianças e adolescentes forem mais assíduos às aulas. No entanto, a defasagem se relaciona com múltiplos determinantes, de fatores ligados às próprias crianças bem como as características da família e da escola ${ }^{41}$. O foco de atuação de políticas públicas não se deve atrelar ao combate à reprovação, inclusive porque nem toda reprovação se dá por causas pedagógicas. Regularizar o tempo de permanência do aluno em sala pode não ser suficiente para aumentar o desempenho ${ }^{42} \mathrm{e}$ pode tornar-se inútil face o baixo nível de aprendizagem que a repetência é incapaz de alterar ${ }^{10}$.

Os resultados escolares, a melhora de seus processos internos e da qualidade de ensino são fortemente influenciados pela origem social e cultural dos alunos matriculados ${ }^{43}$. Uma vez que se considera que a proporção de beneficiários pode alterar os resultados da escola, todos os estudos que utilizaram a escola como unidade, procuraram estabelecer e aferir como as características da escola (equipamentos didáticos, instalações, tamanho da turma, nível de especialização dos educadores) relacionam-se com os indicadores educacionais e se houve modificação destes com a presença de beneficiários. $\mathrm{O}$ impacto do PBF sobre matriculas, aprovação e abandono se operam de modo cumulativo ao longo do tempo com implicações em futuros resultados educacionais $^{22}$.

Com isso, o Ideb, a Prova Brasil e o Censo Escolar constituem instrumentos válidos de registros de informações para avaliações de indicadores escolares. Sendo que o Ideb ainda tem a vantagem de ser de fácil compreensão, simples de calcular, aplicável às escolas e explícito em relação à "taxa de troca" entre probabilidade de aprovação e proficiência dos estudantes ${ }^{37}$. Como medida de qualidade da educação, devem-se ponderar as consequências do Ideb para a escola já que este pode excluir as escolas e ao mesmo tempo as estigmatizar. Os três níveis de avaliação (sistema, escola e sala de aula) devem estar trabalhando articuladamente e segundo as suas respectivas áreas de abrangência ${ }^{42}$.

Outros aspectos da análise das escolas relevase que os artigos utilizaram modelos interativos de estimação de efeitos ${ }^{22,23,24,30}$, em que verificaram se a presença de beneficiários na escola altera ou não o desempenho em exames padronizados ou em taxas de matrícula, aprovação e/ou evasão. Esses efeitos podem variar em relação à criança, dado o caráter de vulnerabilidade familiar, variação da utilização do beneficio e probabilidade da redução da desigualdade de renda e controle da 
criminalidade. Quando alunos socialmente desprotegidos são incorporados nas escolas têm-se a redução de possibilidades de sucesso escolar, já que essa incorporação requer investimentos nas escolas para torná-las mais atraentes e capazes de reter alunos, com atividade extracurriculares e de apoio à aprendizagem dos alunos de menor desempenho ${ }^{10,44}$.

$\mathrm{Na}$ América Latina e em países asiáticos, os programas de transferência de renda, que também estabelecem contrapartidas à população, encontraram impacto positivo sobre a área educacional de seus beneficiários com resultados de aumento de pontos percentuais nas taxas de matriculas escolares no país ${ }^{45}$ e com efeito positivo sobre a frequência escolar ${ }^{46}$.

Em termos de políticas públicas, a universalização com qualidade social, por meio de ações que visem à inserção de todos no processo de educação, com garantia de acesso e assistência à permanência voltada à diversidade socioeconômica dos alunos, propiciam meios de forma a melhorar o desempenho escolar, tanto para o ensino fundamental como o médio ${ }^{47}$. Para desfrutar de políticas e ações com qualidade dentro do ensino, o poder público deve garantir um conjunto integrado de programas, materiais, referências curriculares e pedagógicas que contribuam para $o$ acesso a bens culturais e ao saber historicamente produzido, tendo como eixo principal a formação de professores, de condições físicas da escola, condições de acesso e permanência concomitantes com a garantia de acesso aos demais serviços básicos de direito social e sua de conexão inclusão social e distribuição de renda para os alunos e suas famílias ${ }^{12}$.

Para a avaliação da qualidade do planejamento metodológico do estudo deve-se considerar a aplicação de escalas como um passo importante na realização da RS, embora não haja um consenso na escolha do instrumento bem como na avaliação de escore total para cada trabalho ou item, visto ainda as particularidades do tipo de evidência produzidas pelos estudos ${ }^{18,48}$. Entretanto, optamos pela utilização de uma escala, mesmo que adaptada, para que houvesse a ampliação da visão geral sobre as principais escolhas de metodologias utilizadas pelos autores dos estudos, bem como proporcionar meios de verificação qualitativa para metodologias diversas ou heterogêneas. Para a revisão realizada neste estudo, como quaisquer outros trabalhos que utilizam fontes secundárias, a revisão sistemática esteve limitada a disponibilidade de informações extraídas dos estudos selecionados.

\section{Conclusão}

Para a exploração do tema sobre o impacto do Programa Bolsa Família na educação, a revisão sistemática realizada incluiu um grande número de entradas nas bases de dados no seu início, foi finalizada com apenas 51 trabalhos para análise do texto completo e com número ainda menor para análise final $(\mathrm{n}=12)$. Esse número final é parcialmente explicado pela recente implantação nacional Programa Bolsa Família. Os resultados apresentados nesta revisão sistemática sugerem que há evidências de que o PBF impacta de maneira significativa e assertiva principalmente em indicadores educacionais diretamente atrelados à condicionalidade do Programa Bolsa Família, como a frequência escolar e consequentemente nas taxas de abandono escolar. Esses achados estão associados a critérios intrínsecos à realidade local do aluno e das condições de infraestrutura, plano e equipe pedagógica da escola, ou seja, não relacionados diretamente à condicionalidade do Programa Bolsa Família.

A organização e a otimização dos processos pedagógicos e a melhoria da qualidade da educação devem ser balizados por propostas inovadoras e pautadas pela inclusão social. As metas do Ideb são muito mais difíceis de serem atingidas nas escolas que possuem mais alunos com condições socioeconômicas desfavoráveis. Entretanto, as considerações aqui expostas sinalizam um conjunto de fatores significativos que só mudará na medida em que políticas sociais e de educação tenham sucesso. Sendo, por isso, importante a realização de novos trabalhos para que se obtenha mais clareza e percepção da ação da obrigatoriedade da frequência e matrícula escolar no desenvolvimento da prática e desempenho escolar de beneficiários.

Ademais, os diferenciais de gênero, raça/cor, meio urbano ou rural na distribuição da pobreza identificados nesta pesquisa reforçam a necessidade de melhoramento no uso dos indicadores educacionais (principalmente desempenho e proficiência escolar) que tenham perspectiva multidimensionais da pobreza. Isso pode contribuir para ultrapassar compreensões parciais e muitas vezes distorcidas das condições dos programas sociais e seus beneficiários.

Por fim, atenta-se aqui, ainda, que apesar das principais condicionalidades do PBF, tais como saúde e educação, possuírem público-alvo em faixas etárias diferentes, a boa saúde de uma criança é de extrema importância para o seu bom desempenho escolar. Assim, as condicionalidades 
constituem indicadores sociais importantes na compreensão da realidade local e na construção do diagnóstico situacional de seus beneficiários. Esse diagnóstico pode ser acrescido aos indicadores de saúde, de desempenho escolar, censos e inquéritos escolares de modo a se construir a intersetorialidade dos serviços, o que torna a equipe de saúde da atenção básica bem articulada com os profissionais da educação.

\section{Colaboradores}

MCS Santos contribuiu com a concepção e projeto, revisão bibliográfica, redação do artigo e aprovação final. MGB Ceccato contribuiu com a redação do artigo, revisão crítica do conteúdo e aprovação final da versão a ser publicada. LR Delatorre com a revisão bibliográfica e aprovação final da versão a ser publicada. PF Bonolo contribuiu com a concepção e projeto, revisão bibliográfica, revisão crítica do conteúdo intelectual e aprovação final da versão a ser publicada.

\section{Agradecimentos}

Os autores agradecem ao Conselho Nacional de Desenvolvimento Científico e Tecnológico (CNPQ) pela bolsa de iniciação científica. 


\section{Referências}

1. Brasil. Lei Ordinária no 10.836 , de 9 de janeiro de 2004 . Cria o Programa Bolsa Família, altera a Lei no 10.689 e dá outras providências. Diário Oficial da União 2004; 9 jan.

2. Brasil. Decreto no 5.209, de 17 de setembro de 2004 . Regulamenta a Lei no 10.836, de 9 de janeiro de 2004, que cria o Programa Bolsa Família, e dá outras providências. Diário Oficial da União 2004; 17 set.

3. Brasil. Ministério do Desenvolvimento Social e Combate à Fome. Secretaria Nacional de Renda de Cidadania (Senarc). Manual de Gestão do Cadastro Único para Programas Sociais do Governo Federal. Brasília: Senarc; 2012.

4. Costa DJ, Cunha MS. O Programa Bolsa Família e a oferta de trabalho: evidências para o Brasil e Paraná. Revista de Economia, 2014; 40(2):105-128.

5. Signorini BA, Queiroz BL. The Impact of Bolsa Familia Program in the beneficiary fertility. Belo Horizonte: Cedeplar/UFMG; 2011. (Texto para discussão 439).

6. Rasella D. Aquino R. Santos, C.A. Paes-Sousa, R. Barreto, M.L. Effect of a conditional cash transfer programme on childhood mortality: a nationwide analysis of Brazilian municipalities. Lancet 2013; 382 (9886):5764.

7. Mesquita SP, Ramalho HMB. Trabalho infantil no Brasil urbano: qual a importância da estrutura familiar? Rev Econ Contemp, 2015; 19(1):97-134.

8. Barbosa ALNH, Corseuil CHL. Bolsa família, escolha ocupacional e informalidade no Brasil. Brasília: Instituto de Pesquisa Aplicada (IPEA); 2014. (Texto para discussão 1948).

9. Engle PL, Fernald LCH, Alderman H, Behrman J, O’Gara C, Yousafzai A, Mello MC, Hidrobo M, Ulkuer N, Ertem I, Iltus S; Global Child Development Steering Group. Strategies for reducing inequalities and improving developmental outcomes for young children in low-income and middle-income countries. Lancet 2011; 378(9799):1339-53.

10. Sousa CP. A relevância dos indicadores educacionais para a educação básica: informações e decisões. In: Sousa CP. Dimensões da avaliação educacional. Petrópolis: Vozes; 2005. p. 90-109.

11. Fonseca GLB. Qualidade dos indicadores educacionais para avaliação de escolas e redes públicas de ensino básico no Brasil [dissertação]. Juiz de Fora: Universidade Federal de Juiz de Fora; 2010.

12. Brasil. Ministério da Educação (MEC). Fórum Nacional da Educação. Educação brasileira: indicadores e desafios-documento de consulta. Brasília: MEC; 2013.

13. Corrêa NS. As contribuições do programa bolsa família: inclusão e permanência escolar. In: Seminário de Pesquisa em Educação da Região Sul, ANPED; 2012; Caxias do Sul.

14. Shadish WR, Cook TD, Campbell DT. Experimental and quasi-experimental designs for generalized causal inference. Boston: Houghton Mifflin Company; 2002.
15. Microsoft Office Excel [computer program]. Version 2010. Microsoft Cor, United States.

16. Higgins JPT, Green S. Cochrane handbook for systematic reviews of interventions 5.1. 0 [updated March 2011]. London: The Cochrane Collaboration; 2011.

17. Liberati A, Altman DG, Tetzlaff J, Mulrow C, Gøtzsche PC, Ioannidis JPA, Clarke M, Kleijnen J, Moher D. The PRISMA statement for reporting systematic reviews and meta-analyses of studies that evaluate healthcare interventions: explanation and elaboration. BMJ 2009; 339:b2700.

18. Downs SH, Black N. The feasibility of creating a checklist for the assessment of the methodological quality both of randomised and non-randomised studies of health care interventions. I Epidemiol Community Health 1998; 52(6):377-384.

19. Melo RMS, Duarte GB. Impacto do Programa Bolsa Família sobre a frequência escolar: o caso da agricultura familiar no Nordeste do Brasil. Rev Econ Sociol Rural 2010; 48(3):635-657.

20. Cavalcanti D, Costa E, Silva J. Programa Bolsa Família e o nordeste: impactos na renda e na educação, nos anos de 2004 e 2006. Rev Econ Contemp 2013; 17(1):99-128.

21. Pellegrina H. Impacto de curto prazo do Programa Bolsa Família sobre o abandono e o desempenho escolar do alunado paulista [dissertação]. São Paulo: USP; 2011.

22. Glewwe P, Kassouf AL. The impact of the BolsaEscola/Família Conditional Cash Transfer Programm on Enrollment, Drop Out Rates and Grade Promotion in Brazil. Journal of Development Economics 2012, 97:505517.

23. Simões AA, Sabates R. The contribution of Bolsa Família to the educational achievement of economically disadvantaged children in Brazil. International Journal of Educational Development 2014; 39(0):141-156.

24. Camargo PC, Pazello ET. Uma análise do Programa Bolsa Família sobre o desempenho médio das escolas brasileiras. Economia Aplicada 2014; 18(4):623-640

25. Amaral EFL, Monteiro VP. Avaliação de Impacto das condicionalidades de educação do Programa Bolsa Família (2005 e 2009). Dados 2013; 56(3):531-570.

26. Cacciamali MC, Tatei F, Batista NF. Impacts of the Bolsa Família Program on child labor and school attendance. Rev econ contemp 2010; 14(2):269-301.

27. Oliveira LFB, Soares SSD. O Impacto do Programa Bolsa Família Sobre a Repetência: Resultados a Partir do Cadastro Único, Projeto Frequência e Censo Escolar. Brasília: Instituto de Pesquisa Aplicada (IPEA); 2013.

28. Ribeiro R, Cacciamali M. Impactos do Programa Bolsa Família sobre os indicadores educacionais. Revista Economia 2012; 13(2):415-446.

29. Santarrosa R. Impacto das Transferências Condicionadas de Renda sobre a proficiência dos alunos do Ensino Fundamental no Brasil [dissertação]. São Paulo: Fundação Getúlio Vargas, Escola de Economia de São Paulo; 2011. 
30. Duarte NS. The impact of poverty on Ideb: multilevel study. Rev Bras Estud Pedagog 2013; 94(237):343-363.

31. Silva AP, Brandão A, Dalt S. Educação e pobreza: o impacto das condicionalidades do Program Bolsa Família. Revista Contemporânea de Educação 2012; 4(8):301318.

32. Senna MCM. Ações intersetoriais envolvendo assistência social e saúde: o Programa Bolsa Família em questão. O social em questão 2013; 17(30):245-272

33. Mariano SA, Carloto CM. Aspectos diferenciais da inserção de mulheres negras no Programa Bolsa Família. Soc. Estado 2013; 28(2):393-417.

34. Silveira FG, Horn RV, Campolina, B. Impactos do Bolsa Família na alocação do tempo entre escola e trabalho de crianças e adolescentes de 10 a 18 anos. In: Seminário sobre Economia Mineira, 2014. Cedeplar/UFMG. Belo Horizonte/MG

35. Barrientos A, Debowicz D, Woolard I. Heterogeneity in Bolsa Família outcomes. Quarterly Review of Economics and Finance. Swansea: Swansea Universtity; 2016.

36. Brooke N, Cunha MA. A avaliação externa como instrumento da gestão educacional nos estados. Estudos \& Pesquisas Educacionais 2011; 2:17-79.

37. Fernandes R, Gremaud AP. Qualidade da educação: avaliação, indicadores e metas. In: Veloso F, Pessôa AS, Henriques R, Giambiagi F, organizadores. Educação básica no Brasil: Construindo o país do futuro. Rio de Janeiro: Elsevier; 2009. p. 213-238.

38. Brasil. Todos pela Educação. Resultados do Ideb com foco na equidade e na qualidade das redes públicas do país: Nota técnica dos dados e análises complementares. São Paulo: [s.n.]; 2010.

39. Schettini BP. Eficiência técnica dos municípios brasileiros na educação pública: escores robustos e fatores determinantes. Brasília: Instituto de Pesquisa Aplicada (IPEA); 2014. (2001 Texto para discussão).

40. Machado DL, Knorst PAR. A gestão democrática presente na escola do campo: o caso da Escola de Ensino Fundamental Linha Biguá - SC. Unoesc \& Ciência ACHS 2010; 1(2):111-120.

41. Souza MF. Desigualdade e desempenho: uma introdução à sociologia da escola brasileira, de Maria Lígia de Oliveira Barbosa. Est Aval Educ 2010; 21(46):407411.

42. Freitas LC. Eliminação adiada: o ocaso das classes populares no interior da escola e a ocultação da (má) qualidade do ensino. Educ. Soc, Campinas 2007; 28(100):965-987.

43. Bourdieu P, Passeron JC. A reprodução: elementos para uma teoria do sistema de ensino. Petrópolis: Vozes; 2008.

44. Chioda L, Mello JMP, Soares RR. Spillovers from conditional cash transfer programs: Bolsa Família and crime in urban Brazil. Economics of Education Review 2016; 54:306-320.
45. Schultz P. School subsidies for the poor: evaluating the Mexican Progress poverty program. Journal of Development Economics 2004; 74(1):199-250

45. Parker S, Skoufias E. The impact of Progress on work, leisure and time allocation. Final Report, International Food Policy Research Institute, 2000. Available from: http://ebrary.ifpri.org/cdm/ref/collection/ p15738coll2/id/125439

46. Ravallion M, Wodon Q. Does child labour displace schooling? evidence on behavioural responses to an enrollment subsidy. The Economic Journal 2000; 110(462):158-175.

47. Kuenzer AZ. O ensino médio no plano nacional de educação 2011- 2020: superando a década perdida? Educação \& Sociedade 2010;31(112):851-873

48. Juni P, Altman D, Egger M. Assessing the quality of randomized controlled trials. In: Egger M, Smith GD, Altman D, editors. Systematic Reviews in Health Care. Metanalysis in context. London: BMJ Books; 2001. p. 87-105.

Artigo apresentado em 26/05/2016

Aprovado em 12/09/2017

Versão final apresentada em 14/09/2017 
